\title{
Uma pesquisa aplicada na identidade da marca 0 caso de organização pública de ensino no Brasil
}

\author{
Brand identity applied research: the case of Brazil's Public Education Organization
}

\section{Una investigación aplicada de la identidad de la marca: el caso de la Organización de Pública de Enseñanza en Brasil}

\section{RESUMO}

Este artigo é fruto de uma pesquisa empírica realizada com o intuito de analisar os fatores que contribuem para a identidade da marca de Organização Pública de Ensino (OPE) no Brasil. A identidade de marcas propicia novo paradigma de gestão para organizações públicas, visando à atualização dos mecanismos de comunicação e a proteção da coesão organizacional. A pesquisa realiza estudo de caso em instituição pública de ensino brasileira, sendo feitas, para a consecução do objetivo, entrevistas com os gestores da organização, seguindo um roteiro estruturado. Tal método permitiu a obtenção de resultados que apontam a necessidade de adaptação dos conceitos de gestão empresarial para organizações públicas e a não existência de evidências de gestão da marca e da construção de sua identidade.

Palavras-chave: identidade de marcas; gestão pública; gestão de organizações de ensino.

Isabela Menezes da Silva Devonish - isabela.menezes@gmail.com

Programadora Visual do Centro Federal de Educação Tecnológica Celso Suckow da Fonseca, Divisão de Programação Visual, Rio de Janeiro, RJ, Brasil.

Osvaldo Luiz Gonçalves Quelhas - quelhas@latec.uff.br

Universidade Federal Fluminense, Escola de Engenharia, Laboratório de Tecnologia, Gestão de Negócios e Meio Ambiente, Niterói, RJ, Brasil.

Sérgio França - sfranca@latec.uff.br

Universidade Federal Fluminense, Escola de Engenharia, Departamento de Engenharia Civil, Laboratório de Tecnologia, Gestão de Negócios e Meio Ambiente, Niterói, RJ, Brasil.

Marcelo Meiriño - marcelo@latec.uff.br

Professor Adjunto da Universidade Federal Fluminense, Escola de Engenharia, Niterói, RJ, Brasil.

Artigo submetido no dia 06-01-2015 e aprovado em 21-07-2015.

DOI: http://dx.doi.org/10.12660/cgpc.v20n66.42476 


\section{ABSTRACT}

This paper describes an empirical research project conducted in order to analyze the factors that contribute to the brand identity of Brazil's Public Education Organizations. Brand identity provides a new management paradigm for public organizations, aimed at updating the communication mechanisms and protecting organizational cohesion. The research conducted a case study in a Brazilian public education institution. To achieve its goal, the managers of the organization were interviewed, following a structured script. This method allowed results to be obtained that indicate the need to adapt business management concepts in public organizations and the lack of any evidence of brand management or the construction of identity in them.

Keywords: brand identity; public management; education organization management.

\section{RESÚMEN}

En el presente artículo se describe una investigación empírica que ha sido conducida con el objetivo de analizar los factores que contribuyen para la identidad de marca de la Organización Pública de Enseñanza (OPE) en Brasil. La identidad de marcas propicia un nuevo paradigma de gestión para organizacciones públicas, pretendiendo la actualización de los mecanismos de comunicación y la protección de la cohesión organizacional. La investigación realiza un estudio de caso en una OPE brasileña, habiendo sido realizadas, para la consecución del objetivo, entrevistas con los gestores de la organización, siguiendo una guía estructurada. Dicho método ha permitido la obtencion de resultados que señalan a la necesidad de adaptación de los conceptos de gestión empresarial para organizaciones públicas y a la inexistencia de evidencias de gestión de marca y de la construcción de su identidad en referidas instituciones.

Palabras clave: identidad de marcas; gestión pública; gestión de organizaciones de enseñanza.

\section{INTRODUÇÃO}

O conceito de marca costuma causar dúvidas, impossibilitando atingir toda a potencialidade de vantagens de uma gestão correta. $\mathrm{O}$ fato de uma organização possuir logotipo ou símbolo é diferente de ter uma marca, que, segundo Martins (2006), inclui aspectos intangíveis, complexos e de grande visibilidade. É necessário, para seu diagnóstico, estudar questões associadas a: produtos ou serviços relacionados, mercados, público-alvo, segmentação dos consumidores, aspectos relevantes de pesquisas de mercado e de imagem, marcas concorrentes, suas vantagens ou desvantagens, descrição dos atributos do produto ou do serviço, associações existentes, vantagens, benefícios ou diferenciais competitivos, históricos de satisfação e insatisfação dos públicos da marca, entre outras.
Embora não seja possível igualar instituições públicas e privadas, por causa das diferenças nos objetivos, focos, públicos-alvo etc., poderia ser vantajoso para o serviço público a apropriação e a adequação de uma abordagem empresarial. O que ocorre na realidade, no entanto, segundo Sá (2005), é que a maioria dos órgãos públicos possui modelos de gestão sem fundamento científico, com base na intuição de gestores, não sendo a gestão da marca exceção.

Iniciativas realizadas na gestão pública no Brasil, como o Portal da Transparência, o Programa de Qualidade do Setor Público (PQSP), o Banco de Boas Práticas da Gestão Pública e o Concurso Inovação na Gestão Pública Federal, buscam a atualização de valores organizacionais, por meio da adaptação de ferramentas e processos característicos da gestão empresarial nas instituições públicas. Essas iniciativas propiciam definir a 
identidade das organizações públicas e consequente adequação da imagem, de modo a melhorar a interface com o público. Nesse sentido, Neves (2001) aponta como "um dos pontos para um novo paradigma de gestão para instituições públicas a atualização dos mecanismos de comunicação, para proteger a coesão organizacional."

Destaca-se que as imagens interna e externa da marca estão interligadas. Assim, para um impacto na percepção da imagem externa da organização pública, seus servidores devem estar satisfeitos e motivados, o que não ocorre atualmente, como destaca $\mathrm{Ne}$ ves (2001) ao apontar que:

O clima social atual na administração pública é de forte desmotivação e, sobretudo, de insatisfação dos trabalhadores com base na descrença no valor do serviço público e nas competências e capacidades próprias ou, pelo menos, no seu uso e desenvolvimento, bem como no não reconhecimento da legitimidade das chefias nos campos da direção e liderança (Neves, 2001:26).

Segundo Laing (2003) as Organizações Públicas não priorizam a gestão de sua marca, pois seria uma prática considerada demasiadamente comercial, quanto à sua origem e natureza. Mesmo existindo logotipo, normalmente desenvolvido sem projeto ou critérios como abordagem sistêmica, não há enfoque nas "fontes criadoras de imagem", quer a comunicação social, quer a relação direta com os serviços (Neves, 2001). Assim, é necessária uma revisão da infraestrutura organizacional para modificar a percepção dos funcionários, de modo a torná-los divulgadores e agentes dos valores da marca, já que, no caso de dissonância entre mensagem e experiência, a experiência negativa deve prevalecer no imaginário do usuário.

Como agravante, em geral, organizações públicas "não possuem uma cultura e um ambiente voltados para a aprendizagem organizacional" (Coelho, 2004:102), apresentando resistência a mudanças, o que restringe a inovação no serviço público. É de extrema importância para qualquer organização pública conhecer o meio social, econômico e cultural no qual atua, adaptando-se aos desafios e oportunidades que surgem (Neves, 2001).

Assim, há necessidade de definir a identidade da marca das Organizações Públicas e sua gestão adequada, em especial quando se aborda um setor de relevância para a sociedade, como a educação, para transmitir de forma justa um novo conceito de instituição pública, ajudando a melhorar a imagem do serviço público junto à sociedade e levando "à ampliação das expectativas de serviço por parte dos cidadãos-usuários" (Sá, 2005:43).

Este trabalho conjuga pesquisa de literatura científica e documental para orientar estudo de caso em instituição pública de ensino brasileira, objetivando identificar aspectos e características da identidade e da gestão de marcas em OPEs - por meio da interpretação da visão atual dos gestores sobre a instituição e da verificação de como é definida sua identidade e gerida a marca -, de modo a fortalecer sua imagem em relação à sociedade.

Tal método permitiu a obtenção de resultados que apontam a necessidade de adap- 
tação dos conceitos de gestão empresarial para organizações públicas, uma vez que nelas não há evidência de gestão da marca e da construção de sua identidade, sem mencionar os problemas quanto à motivação, à identificação com a instituição e à percepção de autoestima do servidor público, apesar da comprovada importância de uma gestão interna da marca.

O artigo é composto por seis seções: (1) introdução ao tema proposto; (2) revisão de literatura, reunindo conhecimentos sobre gestão pública, gestão de marcas e possíveis interseções; (3) exposição do método utilizado; (4) apresentação dos resultados encontrados; (5) discussão desses resultados; (6) conclusão e sugestões para novas pesquisas. A delimitação deste estudo é definida pelo período em que foi realizada a pesquisa de campo: nos anos de 2012 e 2013 e pela localização da OPE estudada, no Estado do Rio de Janeiro, Brasil.

\section{REVISÃO DA LITERATURA}

O estudo de gestão da marca é relativamente recente, apresentando, no entanto, progressiva expansão a partir dos anos de 2000. Para coletar artigos relevantes sobre o tema, foram feitas pesquisas nas bases Scopus e ISI com as palavras-chave: brand, education, public, services e suas combinações. Com o intuito de procurar bases para o projeto, foram consideradas as discussões sobre gestão de marcas em instituições públicas (independentemente da área de atuação) e gestão de marcas em instituições de ensino (em geral, particulares ou mistas).

\subsection{GESTÃO PÚBLICA}

As organizações públicas têm, em seus propósitos eminentemente sociais, conforme Neves (2001), diferenças cruciais em relação às empresas privadas. Em primeiro lugar, como empresas privadas, "buscam a conquista de mercados e o lucro crescente para seus proprietários", instituições públicas "existem para atender às demandas políticas e sociais das comunidades de sua área de atuação formadas por entes públicos (estados, municípios etc.)" (Sá, 2005, p. 22). Ou seja, o destinatário final que para as empresas privadas é centrado em determinado público-alvo, para instituições públicas envolve, além do governo em seus diversos níveis, os cidadãos que, como explica Neves (2001, p. 65), assumem em relação aos serviços públicos diferentes tipos de relação, desde relações de cidadania até a de contribuinte, de cliente ou beneficiário de um serviço.

Além disso, a visão e o enfoque se diferenciam muito: instituições públicas apresentam geralmente foco em si mesmas, seus processos e serviços (burocracia) - geralmente sem focalizar os indivíduos e suas necessidades (Coelho, 2004, p. 110) - e sua eficiência associada ao atendimento das demandas da sociedade. Possui traços como: negligência em relação ao interesse público; excesso de gastos; desperdícios; falta de interesse direto na obtenção de resultados; monopólio de funções; adoção de políticas convenientes a interesses próprios (Martins, 1996) e ainda:

Ausência de foco no cliente do serviço público (o cidadão); inexistência de objetivos claros, bem definidos e disseminados; processos e atividades não documentados e nem otimizados; servidores e setores que não conhecem bem suas atribuições; servidores que não conhecem o papel da 
organização, que não participam de processos, ações e soluções dos problemas - e que não são capacitados devidamente para desempenhar suas funções; inexistência de formas de medir e avaliar constantemente os processos para meIhorá-los; decisões e ações que não são constantemente avaliadas e, por isso, que não realimentam correções; informações não circulam de maneira ágil e correta entre servidores e setores; inexistência de preocupação constante com inovação e mudança (Batista, 2004, pp. 8-9).

\subsection{GESTÃO DE MARCAS}

Martins (2006:8) afirma que a gestão de marcas envolve ações que conduzem as marcas além da natureza econômica, passando a fazer parte da cultura e a influenciar a vida das pessoas. Segundo Aaker (2007, pp. 73-75), a identidade da marca é um conjunto exclusivo de associações com a marca que o estrategista ambiciona criar ou manter. Essas associações representam aquilo que a marca pretende realizar e implicam uma promessa aos clientes, feita pela organização. No entanto, a criação da identidade de marca é algo mais abrangente do que descobrir o que os clientes dizem querer, pois deverá espelhar também o espírito e a visão da marca.

\section{Identidade da Marca}

Segundo Vásquez (2011) e Wheeler (2003), existem duas explicações de por que o consumidor usa determinada marca: porque transmite sensações e o consumidor se identifica ou porque representa algo ao qual o consumidor aspira, algo que o indivíduo não tem e que ela pode lhe proporcionar. $\mathrm{A}$ verdadeira essência da marca está em seu significado, um meio de vida, uma atitude, um conjunto de valores, uma expressão, um conceito. Pessoas não escolhem "produtos", escolhem marcas.

A identidade é a estrutura sobre a qual se constrói a marca. É ela que dá direção, propósito e significado à marca, norteia ações organizacionais e financeiras, define objetivos mercadológicos e comunicacionais e transmite, por meio de símbolos, sentido e conceito. Para cumprir seus propósitos deve ser:

a) única e intransferível: pertencer a uma marca específica. Não existem duas marcas com a mesma identidade.

b) atemporal e constante: não tem limite de validade, devendo ser constante no tempo.

c) consistente e coerente: deve ser sólida em seus elementos constitutivos e, ao mesmo tempo, existir correlação entre eles, sendo congruentes e compatíveis entre si.

d) objetiva e adaptável: deve ser direta em seus propósitos e sua comunicação adaptada de acordo com seu público-alvo.

Aaker (2007) atribui à estrutura da identidade da marca uma parte nuclear e outra externa. A identidade nuclear seria a central, atemporal da marca; constante à medida que ela alcança novos mercados e produtos ou serviços, compondo-se das crenças, dos valores fundamentais e das competências da organização, sendo definida pelo que a marca representa. Já a identidade externa corresponde aos elementos que the conferem tangibilidade e estrutura, mas que são 
mais mutáveis e adaptáveis com o tempo, segundo estratégias.

A inclusão da identidade da marca no plano de construção das marcas, segundo Aaker (2007), é descrito por:

a) análise estratégica da marca

- análise dos consumidores

- análise da concorrência

- autoanálise

b) definição do sistema de identidade da marca

- identidade nuclear

- identidade externa

- considerações da base: proposição de valor, credibilidade, relacionamento

c) implementação da identidade da marca

- determinação do posicionamento

- programas de comunicação

- avaliação dos resultados

Aaker (2007) apresenta método de planejamento e de diagnóstico da identidade da marca a realizar-se em várias etapas, que incluem: (1) identificação das dimensões centrais da marca; (2) consideração da proposição de valor; (3) inclusão de elementos de credibilidade; (4) estabelecimento das bases de relacionamento com o usuário, no sentido da determinação da identidade nuclear e da identidade externa da marca.

\section{Gestão de marcas em Organizações de Ensino}

Segundo Foster, Punjaisri e Cheng (2010), a gestão da marca ganhou maior destaque principalmente devido à era dos serviços, na qual a marca desempenha, como acrescentam Brodie, Whittome e Brush
(2009), um papel maior, fazendo a interface não somente entre empresa e cliente, como também com funcionários e demais partes interessadas. Brodie, Whittome e Brush (2009) sustentam que a marca de serviços é "um processo holístico, iniciado com a relação entre a empresa e seus funcionários e ganhando vida durante a interação entre funcionários e clientes", podendo ser considerado, dessa forma, uma cocriação (Brodie, Whittome e Brush, 2009).

Como principais diferenças de serviços, $\mathrm{Ng} \mathrm{e}$ Forbes (2009) apontam efemeridade, intangibilidade, inerência entre produção e consumo e heterogeneidade na entrega, contando ainda com poucos atributos avaliáveis antes da aquisição ( $\mathrm{Ng}$ e Forbes, 2009). A cocriação do serviço é evidente, conforme atentam $\mathrm{Ng}$ e Forbes (2009) em instituições de ensino, sendo alunos, conjuntamente a professores e outros funcionários, responsáveis pelos serviços resultantes. As autoras alertam para os hiatos na entrega do serviço de uma instituição de ensino: a diferença entre o que o aluno espera e o que a instituição pensa que ele espera; entre o que a instituição entende das expectativas dos alunos e o desenvolvimento do serviço; entre o que é desenvolvido e o que de fato é entregue, e entre o que é entregue e o que é comunicado ( $\mathrm{Ng}$ e Forbes, 2009).

Há correntes, como a indicada por $\mathrm{Ng}$ e Forbes (2009), que defendem uma perspectiva orientada ao negócio para instituições de ensino, resumindo os alunos ao papel de clientes, o que pode ser condizente com a cultura dominante atual (Clayson e Haley, 2005), mas perigoso, pois, como relatado no próprio trabalho, o aluno pode se sentir proprietário da experiência de ensino, indepen- 
dentemente de seu esforço e merecimento (Ng e Forbes, 2009). Na perspectiva de cocriação, o aluno participa da criação da experiência de serviço como insumo e produto final, contribuindo para a geração de qualidade, satisfação e valor. Como destacam Durkin, McKenna e Cummins (2012), parece não haver outro serviço no qual o esforço do usuário seja tão determinante para a qualidade, havendo um ambiente de parceria no qual os alunos são um entre vários grupos que determinam como a experiência ocorrerá.

Pinar et al. (2011) evocam o número crescente de instituições de ensino competindo pelos mesmos alunos, local e internacionalmente (Chapleo, 2010), gerando a necessidade, segundo Judson et al. (2008), de diferenciação e comunicação. Assim como a gestão adequada de marcas de consumo atrai e cativa clientes, em instituições de ensino, a gestão da marca pode influenciar sua reputação (Black, 2008) e contribuir na competição pelos melhores alunos e funcionários (Judson et al., 2008; Nguyen,
Shirahada \& Kosaka, 2012), já que prestígio e reputação têm prevalência sobre a qualidade real do serviço (Ivy, 2001; Mazzarol \& Soutar, 1999).

Ivy (2001) afirma que as imagens são formadas, além das práticas de marketing, pelo "boca a boca" e pela experiência direta evocando, segundo Black (2008), uma mudança institucional sistêmica que envolva e engaje professores e demais funcionários, alunos e suas famílias à comunidade e ao governo (Nguyen, Shirahada \& Kosaka, 2012; Heaney \& Heaney, 2008), o que é corroborado por Mazzarol \& Soutar (1999), que afirmam que organizações com culturas fortes ou valores partilhados obtêm desempenho superior.

Experiências registradas na literatura científica são descritas no Quadro 1, que apresenta panorâmica quanto a abordagens de gestão da marca em algumas organizações de ensino e em recomendações realizadas por pesquisadores dedicados à temática. 
Isabela Menezes da Silva Devonish - Osvaldo Luiz Gonçalves Quelhas - Sérgio França - Marcelo Meiriño

Quadro 1 - Síntese das Estratégias de Gestão de Marcas em Organizações de Ensino

\begin{tabular}{|c|c|c|}
\hline Organização & Referência bibliográfica & Gestäo da marca \\
\hline $\begin{array}{lr}\text { Universidade } & \text { de } \\
\text { Denver, } & \text { Estados } \\
\text { Unidos } & \end{array}$ & Mayer (2013) & $\begin{array}{l}\text { Mudou logotipo e site. } \\
\text { Adequou o conteúdo das notícias publicadas. }\end{array}$ \\
\hline $\begin{array}{l}\text { Universidade Anhembi, } \\
\text { Morumbi, São Paulo, } \\
\text { Brasil }\end{array}$ & Nogueira e Portella (2007) & $\begin{array}{l}\text { Promoveu um processo de reposicionamento para } \\
\text { atingir as classes A e B, que envolveu: } \\
\text { - Utilização, para o público interno, de programa de } \\
\text { transparéncia em relação às mudanças na } \\
\text { estratégia organizacional, incluindo ciclos de } \\
\text { palestras para comunicar as mudanças, cultural } \\
\text { e organizacional. } \\
\text { - Desenvolvimento de slogan para traduzir a marca } \\
\text { e campanha publicitária para divulgar o projeto } \\
\text { (incluindo e-mail, site, banners e cartazes). } \\
\text { - Realização de pesquisa de conhecimento da } \\
\text { marca abrangendo todos os campi. } \\
\text { - Treinamento para alinhar as açöes da equipe de } \\
\text { acordo com os atributos da marca. } \\
\text { - Incentivos à motivação, à liderança e à melhoria na } \\
\text { qualidade de vida de funcionários. }\end{array}$ \\
\hline $\begin{array}{l}\text { Universidade de Ulster, } \\
\text { Irlanda, Reino Unido }\end{array}$ & $\begin{array}{l}\text { Durkin, McKenna e Cummins } \\
(2012)\end{array}$ & $\begin{array}{l}\text { - Criou setor de marketing encarregado de } \\
\text { desenvolver novas ideias para diferenciar a } \\
\text { universidade, local e nacionalmente, adotando } \\
\text { abordagem mais emocional, sem, no entanto, } \\
\text { abolir a racionalidade, em uma tentativa de ser a } \\
\text { ponte entre consciência e compreensão da } \\
\text { avaliação de proposição de valor para os } \\
\text { potenciais alunos. } \\
\text { - Produziu propaganda em animação com } \\
\text { personagem cativante. A campanha nacional, em } \\
\text { época específica, utilizou-se de televisão, } \\
\text { outdoors, rádio e site, exibindo a marca da } \\
\text { universidade. }\end{array}$ \\
\hline $\begin{array}{l}\text { Universidades do } \\
\text { Reino Unido e da } \\
\text { África do Sul }\end{array}$ & Ivy (2001) & $\begin{array}{l}\text { - Compara universidades tradicionais do Reino } \\
\text { Unido, universidades modernas do Reino Unido, } \\
\text { escolas superiores de tecnologia da África do Sul. } \\
\text { - As universidades tradicionais do Reino Unido são } \\
\text { orientadas ao produto, com comunicaçäo de } \\
\text { imagem associada à qualidade de ensino, à } \\
\text { pesquisa, à variedade de cursos oferecidos e à } \\
\text { reputaçäo. } \\
\text { - As universidades modernas do Reino Unido têm } \\
\text { foco em "vender" a instituiçäo, empregando } \\
\text { atividades promocionais como mala-direta pelo } \\
\text { correio, abertura do campus para visitaçäo, } \\
\text { ferramentas da web e atividades esportivas. } \\
\text { - As escolas superiores de tecnologia da África do } \\
\text { Sul utilizam as instalações fisicas e propagandas } \\
\text { na imprensa, além da oferta de bolsas de estudo. }\end{array}$ \\
\hline
\end{tabular}

Continua... 
Uma pesquisa aplicada na identidade da marca. $\mathbf{O}$ caso de organização pública de ensino no Brasil

\begin{tabular}{|c|c|c|}
\hline $\begin{array}{l}\text { ERAU, Embry-Riddle } \\
\text { Aeronautical University }\end{array}$ & Curtis, Abratt e Minor (2009) & $\begin{array}{l}\text { - Desenvolvimento de departamento de marketing e } \\
\text { publicidade para formar plataforma única para a } \\
\text { marca nos três campi da universidade. Vários } \\
\text { setores, incluindo a tecnologia da informação, } \\
\text { contribuíram para a tarefa de reconhecimento } \\
\text { global da marca, procurando identificar o que a } \\
\text { universidade é e o que representa. Identifica-se } \\
\text { que o processo de gestão da marca } \\
\text { organizacional aborda três áreas principais: } \\
\text { administração de web, marketing e } \\
\text { posicionamento da marca corporativa. }\end{array}$ \\
\hline $\begin{array}{l}\text { Universidade Osaka, } \\
\text { Japäo }\end{array}$ & $\begin{array}{l}\text { Nguyen, Shirahada e Kosaka } \\
(2012)\end{array}$ & $\begin{array}{l}\text { - Processo de cocriação, envolvendo cinco fases: } \\
\text { (1) compartilhamento de visöes; (2) criaçäo de } \\
\text { atmosfera confortável, promovendo comunicação } \\
\text { efetiva; (3) cocriação de valor por meio do } \\
\text { compartilhamento de visão comum - utilizando } \\
\text { reuniões, redação de artigos e outras atividades; } \\
\text { (4) diagnóstico e soluçäo de problemas, } \\
\text { originando novas ideias e proposta de soluçöes; } \\
\text { (5) mudança de mentalidade e de } \\
\text { comportamento. }\end{array}$ \\
\hline Aplicação genérica & Chapleo (2010) & $\begin{array}{l}\text { - Fatores associados à marca de sucesso em } \\
\text { instituições de ensino: liderança, visão clara dos } \\
\text { objetivos, engajamento do público interno, } \\
\text { relações públicas e sinergia com a comunidade. } \\
\text { Adicionando-se como fatores igualmente } \\
\text { importantes a pesquisa e a experiència com a } \\
\text { marca e as práticas do marketing. }\end{array}$ \\
\hline Aplicação genérica & Pinar et al. (2011) & $\begin{array}{l}\text { - Considera que alunos avaliam a instituição pela } \\
\text { experiència geral, devendo toda a equipe entender } \\
\text { sua importância nas experiências de contato e } \\
\text { interação com os alunos. Não somente a } \\
\text { competência acadêmica é considerada para } \\
\text { valorizaçäo da marca, mas também todas as } \\
\text { atividades de suporte. }\end{array}$ \\
\hline Aplicação genérica & Curtis, Abratt e Minor (2009) & $\begin{array}{l}\text { - Deve coexistir a busca de diferenciação, com o } \\
\text { desenvolvimento do sentimento de "pertencer à } \\
\text { organizaçäo", além da identificação com a marca, } \\
\text { tornando-se um membro do grupo para a vida } \\
\text { toda. }\end{array}$ \\
\hline
\end{tabular}

Fonte: Elaborado pelos autores.

Gestão de Marcas em instituições públicas Esta pesquisa explora a contribuição do público interno, na voz dos gestores das organizações públicas. Observa-se, na literatura científica, a necessidade de alinhar os valores e comportamentos pessoais com os valores da marca, assim como a importância da cultura na construção da marca. A reputação é uma avaliação externa ade- quada de uma marca, sendo possível aos gestores identificar, ao comparar as diferenças entre identidade de marca e reputação, estratégias para minimizar incongruências e desenvolver marcas mais influentes.

Os modelos apresentados na literatura científica são usualmente empregados em organizações particulares, e seus métodos 
podem não ser totalmente adequados ao setor público, por isso a aplicação de conceitos de gestão da marca em instituições públicas é um tópico novo e de adoção delicada, como ressaltam Chen et al. (2004). Qualquer mudança na cultura organizacional na organização pública é tarefa de resultados difíceis de serem alcançados. Pode ser visualizada a importância e utilidade da gestão de marcas na estruturação e expansão da OPE, proporcionando resultados de satisfação e confiança (Whelan et al., 2010): maior conhecimento sobre a organização e serviços oferecidos à sociedade; importância no relacionamento com a comunidade; promoção de seus serviços e maior prestígio, propiciando mais confiança e motivação na equipe (Hood e Henderson, 2005).

Whelan et al. (2010) frisam a limitação, no setor público, de orçamento para promoção ou propaganda, destacando por isso a relevância da orientação ao usuário e o gerenciamento de suas experiências com a organização pública para elevar as associações positivas da marca. Uma gestão orientada ao usuário, conforme descrevem Chen et al. (2004), propõe que a satisfação do usuário deve ser prioridade no objetivo organizacional, pois, quanto mais a orientação ao usuário for percebida, melhor será a imagem da organização na comunidade (Whelan et al., 2010).

Além disso, a orientação ao cliente é um meio de aumentar a moral e encorajar a propriedade do público interno sobre a marca, melhorando a qualidade geral (Hood \& Henderson, 2005) e resultando em maior satisfação interna e externa (Whelan et al., 2010), já que "funcionários insatisfeitos levam a clientes insatisfeitos" (Chen et al.,
2004). Whelan et al. (2010) distinguem duas dimensões na interação do público interno com o usuário: a necessidade, que se reflete na resolução apropriada de problemas, e o prazer, transmitido no atendimento com simpatia. Dessa forma, assim como no setor privado, uma gestão interna da marca no serviço público deve ser considerada interligada à gestão externa (Whelan et al., 2010), sendo de grande relevância para manifestar os contornos da imagem da marca.

\section{MÉTODOS DE PESQUISA}

Esta pesquisa adota uma abordagem exploratória para obter maior conhecimento sobre uma área em que os estudos são escassos: a identidade de marcas em OPEs brasileiras. Segundo Selltiz et al. (1975, p. 60), um estudo exploratório tem a função de aumentar o conhecimento do pesquisador sobre o fenômeno que deseja investigar e de esclarecer conceitos. Considerando-se que o objetivo é realizar análise em profundidade, escolheu-se o procedimento qualitativo, pois ele permite ao pesquisador estudar eventos selecionados de forma detalhada e profunda (Patton, 1990, pp. 13-14). O estudo possui duas vertentes complementares: uma teórica, outra empírica, conforme ilustra a Figura 1.

Figura 1 - Estrutura metodológica da pesquisa

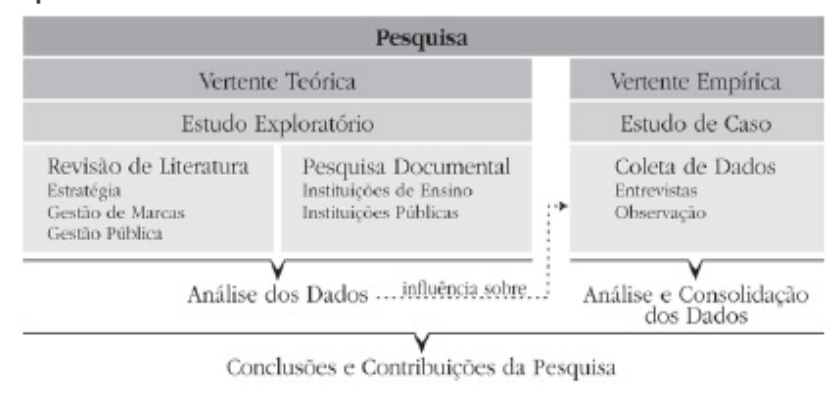

Fonte: Elaborado pelos autores. 
Uma pesquisa aplicada na identidade da marca. 0 caso de organização pública de ensino no Brasil

A vertente teórica do estudo é composta pela pesquisa da literatura científica e documental sobre OPEs, além de incorporar a revisão de literatura científica relacionada à gestão de marcas e identidade, gestão pública e particularidades do serviço educação. A análise dos dados gerados nessas dimensões norteará o desenvolvimento do estudo de caso.

A vertente empírica, por sua vez, investiga - por meio de confrontação de dados e entrevistas estruturadas - um caso representativo de OPE para compreender como é percebida a Identidade de Marcas. $O$ objeto de estudo selecionado foi OPE X, que inclui formação de técnicos e ensino superior, em várias áreas. $\mathrm{O}$ mesmo modelo de gestão adotado na organização estudada é encontrado nas demais unidades da rede no Brasil.

Para a coleta de informação, foi utilizada a triangulação de dados, possibilitada pela variedade de fontes utilizadas:

Para os dados primários:

a) Observação direta, isto é, entrevistas realizadas na sede da organização para que fosse possível observar equipe, condições físicas da sede, localização e estilo. A observação foi individual, assistemática, ou seja, sem controle previamente estabelecido, havendo registro de dados à medida que ocorreram. O resultado das observações, associado às entrevistas, possibilitou uma compreensão mais profunda das relações entre a instituição, sua comunidade interna e sua marca.

b) entrevistas com gestores

c) entrevistas com profissionais que atuam em funções consideradas essenciais para a gestão de marcas (Assessoria de Relações Internacionais; Recursos Humanos; Comunicação Social e Programação Visual). As entrevistas foram semiestruturadas, seguindo um roteiro predeterminado, mas conduzidas de forma espontânea para tentar obter dos entrevistados suas próprias interpretações das estratégias adotadas, dos resultados e da identidade de sua marca.

Para os dados secundários:

- Documentação e registros em arquivo, coletados na mídia e na organização estudada.

\section{RESULTADOS}

As questões propostas foram agrupadas em três blocos, tendo como finalidade: (1) reconhecer a identidade da marca da instituição, ou, na definição de Aaker (2007), a maneira como os estrategistas querem que a marca seja percebida; (2) constatar como é gerida a marca atualmente e quais práticas exercidas são intencionalmente parte de uma gestão da marca; (3) verificar possíveis gaps entre estratégia e prática, identificando quais fatores avaliados como importantes para melhorar a imagem externa e interna da organização não apresentam evidências de estarem incluídos nas práticas da organização.

As perguntas realizadas nas entrevistas se correlacionam com as questões e os objetivos da pesquisa, conforme ilustra o Quadro 2. A seguir, são apresentadas sequencialmente as análises de cada tópico da entrevista. 
Quadro 2 - Correlação das questões da pesquisa versus objetivos versus pergunta da entrevista

\begin{tabular}{|c|c|c|}
\hline Questão da Pesquisa & Objetivo da Pesquisa & Questão incluída na entrevista \\
\hline \multirow[t]{4}{*}{$\begin{array}{l}\text { Como é percebida a marca e } \\
\text { sua gestão em uma } \\
\text { instituição pública de ensino } \\
\text { brasileira? }\end{array}$} & \multirow[t]{2}{*}{$\begin{array}{l}\text { Interpretar a visão atual sobre a } \\
\text { instituição foco do estudo de } \\
\text { caso e sua marca. }\end{array}$} & $\begin{array}{l}\text { O que você diria a um aluno que } \\
\text { pensa em se candidatar a uma } \\
\text { vaga na OPE X? Que vantagens } \\
\text { destacaria? }\end{array}$ \\
\hline & & $\begin{array}{l}\text { O que você diria a um candidato } \\
\text { a uma vaga para trabalhar na } \\
\text { OPE } X \text { ? Que diferenças existem } \\
\text { no ambiente de trabalho? }\end{array}$ \\
\hline & \multirow[t]{2}{*}{$\begin{array}{l}\text { Verificar como é gerida a marca } \\
\text { atualmente na instituição foco } \\
\text { do estudo de caso. }\end{array}$} & $\begin{array}{l}\text { Quais ações vêm sido tomadas } \\
\text { para o crescimento da marca? } \\
\text { Quais os principais setores } \\
\text { envolvidos? }\end{array}$ \\
\hline & & $\begin{array}{l}\text { A que você atribui o sucesso da } \\
\text { marca? }\end{array}$ \\
\hline \multirow[t]{2}{*}{$\begin{array}{l}\text { Quais mecanismos e ações } \\
\text { vêm sendo utilizados? }\end{array}$} & \multirow{3}{*}{$\begin{array}{l}\text { Comparar textos científicos } \\
\text { nacionais, internacionais e o } \\
\text { caso de instituição de ensino } \\
\text { federal brasileira com os } \\
\text { modelos teóricos identificados } \\
\text { na literatura. }\end{array}$} & $\begin{array}{l}\text { Ordene os fatores que mais } \\
\text { influenciam a imagem externa } \\
\text { da OPE } X \text {, em ordem } \\
\text { decrescente. }\end{array}$ \\
\hline & & $\begin{array}{l}\text { Ordene os fatores que mais } \\
\text { influenciam a imagem interna } \\
\text { da OPE } x \text {, em ordem } \\
\text { decrescente. }\end{array}$ \\
\hline $\begin{array}{l}\text { Os mecanismos e as ações } \\
\text { utilizados satisfazem as } \\
\text { necessidades da atual gestão } \\
\text { de marcas em instituições } \\
\text { públicas de ensino? }\end{array}$ & & $\begin{array}{l}\text { Desses fatores, o que deve ser } \\
\text { aperfeiçoado para melhorar a } \\
\text { imagem da organização? }\end{array}$ \\
\hline
\end{tabular}

Fonte: Elaborado pelos autores.

Após as entrevistas, para realização do último passo indicado por Bauer e Gaskell (2002), a análise do corpus do texto, foram utilizadas técnicas de análise de conteúdo (AC), que, como explica Bardin (1977), recorrem à dedução do poder do "não dito" (Bardin, 1977). A intenção da AC, segundo Bardin (1977, p. 38), "é a inferência de conhecimentos... que recorre a indicadores (quantitativos ou não)," procurando assim "conhecer aquilo que está por trás das palavras sobre as quais se debruça" (Bardin, 1977, p. 44).

Um dos métodos indicados por Bardin (1977) é o das categorias, que "permitem a classificação dos elementos de significação constitutivos da mensagem", consistindo "em des- 
cobrir os 'núcleos de sentido' que compõe a comunicação e cuja presença, ou frequência de aparição, pode significar alguma coisa" (Bardin, 1977, p. 105). A partir da categorização, as táticas aplicadas, sugeridas por Bardin (1977), foram presença ou ausência dos temas e sua frequência ponderada, usando como indicadores: ordem de aparição; intensidade da menção ao tema - se o entrevistado apenas citou o fato ou se houve algum tipo de explanação; e direção - se a citação foi positiva, negativa ou neutra.

\section{Reconhecer a identidade da marca}

As frequências absolutas de menção a fatores que, na visão dos entrevistados, justificariam a escolha da instituição pelos alu- nos propõem a qualidade de ensino como principal item, seguido pelo reconhecimento que a escola tem no mercado, sua história, desde a época de Escola Técnica, as oportunidades de emprego e estágio geradas e a possibilidade de um sequenciamento do estudo, devido aos vários níveis presentes na instituição. Outros fatores mencionados durante as entrevistas indicam o fato de ser uma instituição pública, a diversidade de pessoas e ideias, o fácil acesso a professores e servidores, a cidadania na comunidade interna, a maturidade que os alunos adquirem dentro da instituição, sua localização central e os horários das aulas bem definidos como possíveis vantagens do centro (figura 2).

Figura 2 - Frequências absolutas dos fatores em ordem decrescente.

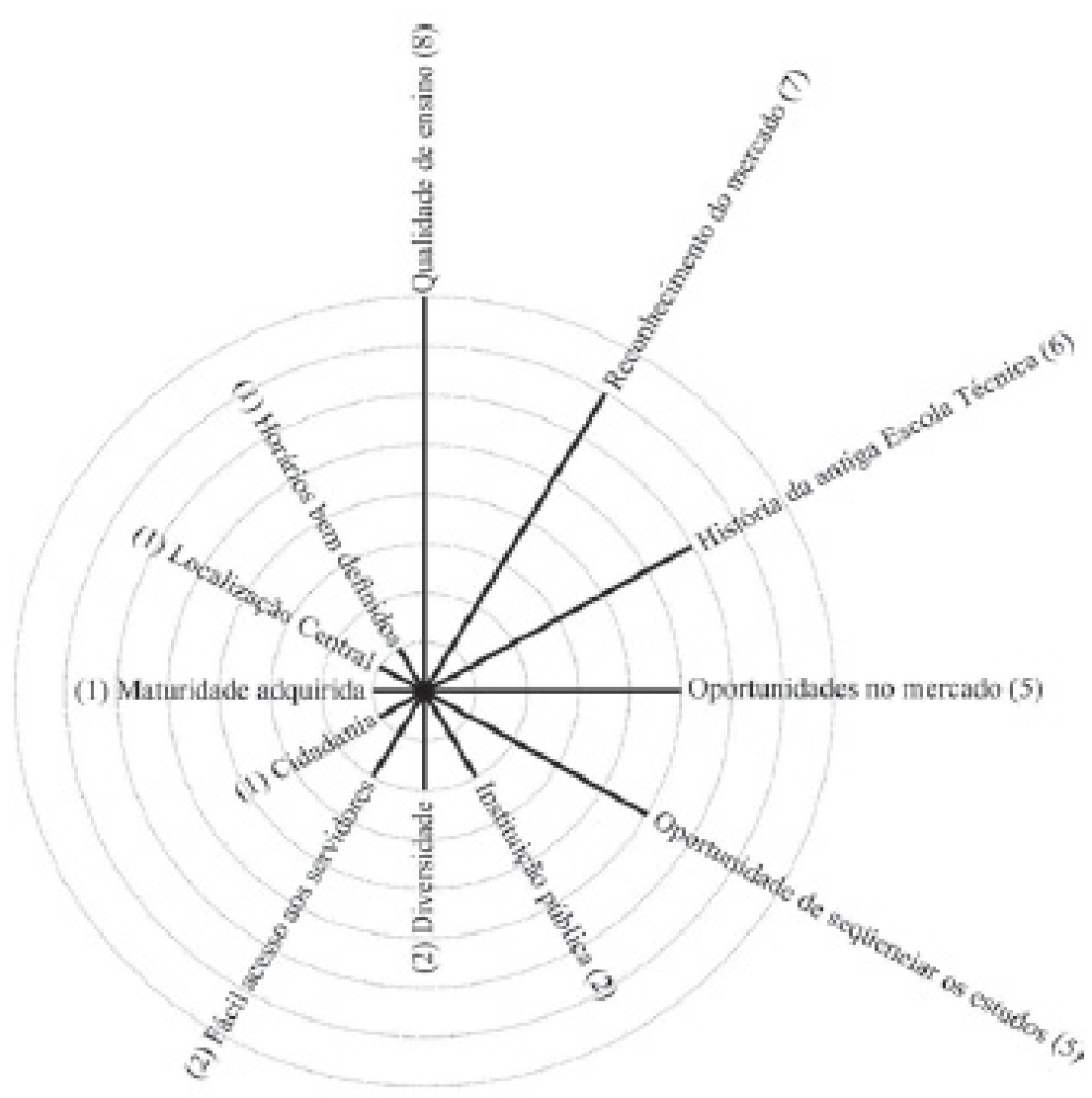

Fonte: Elaborado pelos autores. 
Analisando as frequências ponderadas, considerando o momento em que o fator foi lembrado e a ênfase dada, temos um grande destaque para as oportunidades no mercado geradas pela instituição. A qualidade do ensino e a alusão à história da instituição, segundo e terceiro fatores com maior pontuação, não foram citadas sempre de forma positiva. A qualidade de ensino, embora considerada de alto nível, não foi encarada como diferenciador do centro em relação a outras instituições por alguns entrevistados, enquanto a história da instituição foi interpretada como um fator potencialmente negativo por ter reconhecimento e atuação atuais limitados pelo passado.

É patente que há grande preocupação com a má reputação do servidor público, assim como com as intenções de candidatos às possíveis vagas oferecidas, já que os fatores "má fama do funcionário público" e "conselhos" têm as maiores pontuações. Da mesma forma, o clima amistoso do centro e o crescimento da instituição, o último com menos ênfase, são destaque nas opiniões. A disponibilidade de recursos da própria organização a serem utilizados em projetos e viagens dos professores, a localização central e a rica experiência que pode ser adquirida no ambiente da escola foram também fatores bastante referidos.

Menos citados, há os fatores estabilidade de uma carreira pública, salário e crescimento profissional. Desses, o crescimento profis- sional possibilitado e a segurança de um emprego estável foram mais reforçados nos discursos dos entrevistados. Por fim, horizonte de mudanças no serviço público, agilidade provocada pela proximidade entre as pessoas, contato com vegetação e pequenos animais presentes nos jardins internos e possibilidade de divergências e/ou preconceitos entre as carreiras de docentes e administrativos também foram fatores mencionados.

Esse último fator está presente direta ou indiretamente nas entrevistas seja apenas delimitando diferenças, dando enfoque a apenas uma carreira, seja expondo que as vantagens de trabalho para uma superam as da outra. Em concordância com esta última categoria, nota-se que as duas únicas referências ao salário como um fator de convencimento para trabalhar na instituição reportam-se aos docentes. $O$ destaque para o professor e a interpretação de maior vantagem na carreira docente talvez possam ser justificados pela maior visibilidade dos professores, afinal, em uma instituição de educação a principal expectativa é no ensino.

As figuras a seguir apresentam as frequências absolutas dos fatores em ordem decrescente (figura 3) e as nuvens de palavras das declarações específicas sobre as carreiras docente (figura 4) e administrativa (figura 5). Nessa separação, é visível a maior complexidade na primeira nuvem, demonstrando um discurso mais extenso sobre a carreira docente e suas vantagens. 
Figura 3 - Frequências absolutas dos fatores em ordem decrescente

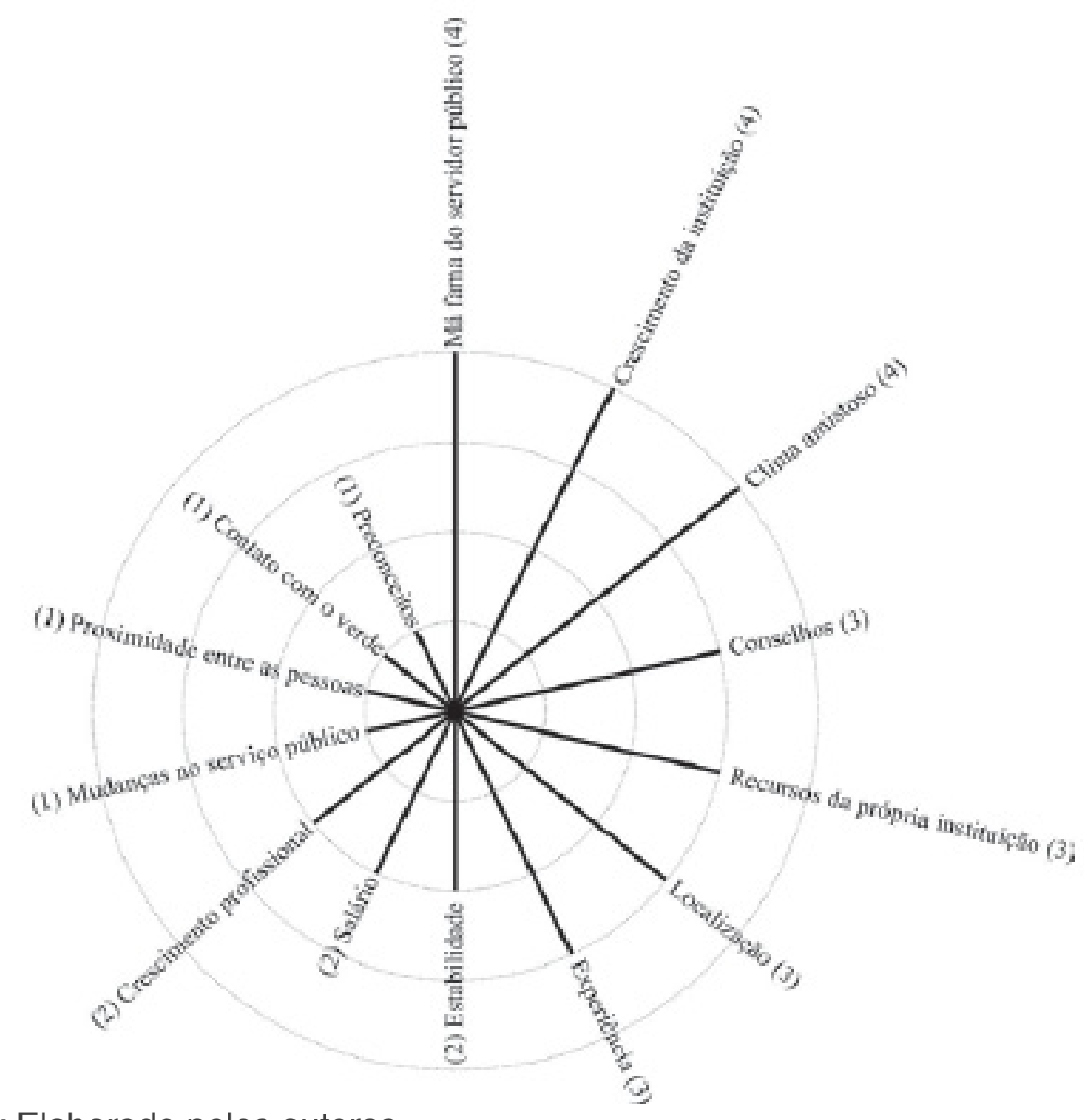

Fonte: Elaborado pelos autores

Figura 4 - Nuvem de palavras com as referências à carreira docente nas respostas

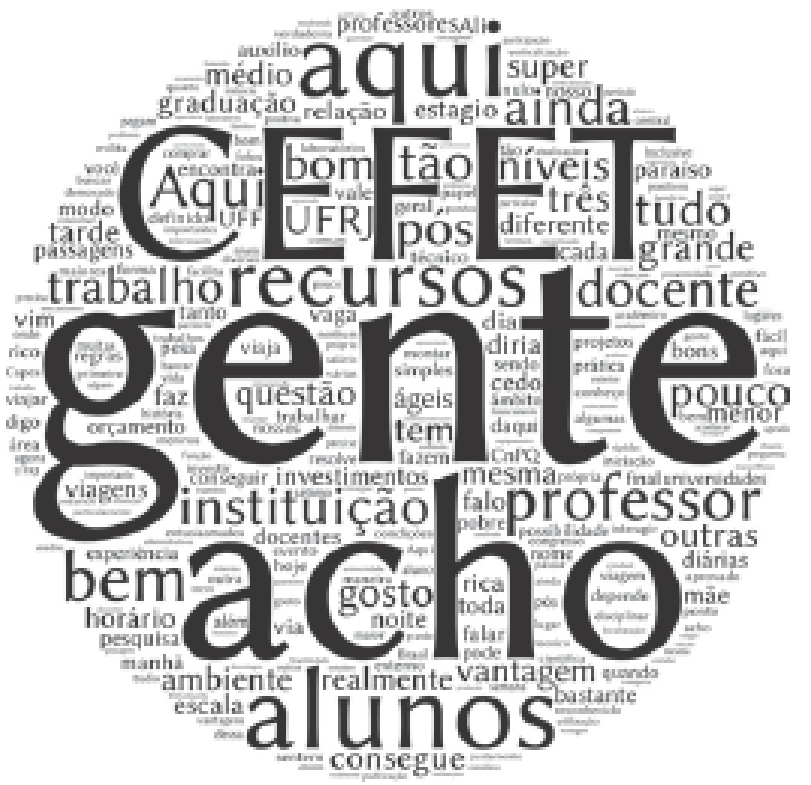

Fonte: Elaborado pelos autores utilizando a ferramenta Tagul Clouds (http://tagul.com/). 
Isabela Menezes da Silva Devonish - Osvaldo Luiz Gonçalves Quelhas - Sérgio França - Marcelo Meiriño

Figura 5 - Nuvem de palavras com as referências à carreira administrativa nas respostas

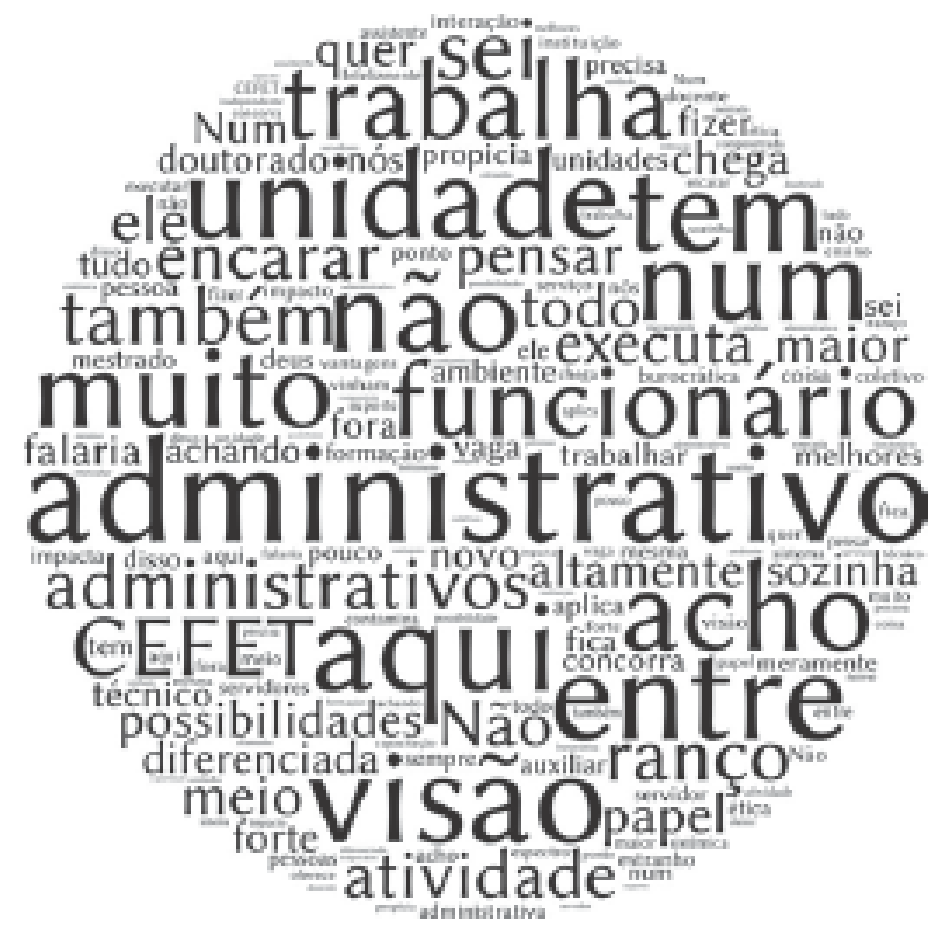

Fonte: Elaborado pelos autores utilizando a ferramenta Tagul Clouds (http://tagul.com/).

Como é gerenciada a identidade da marca

O fator correlacionado ao crescimento da marca da instituição mais citado nas entrevistas foi a divulgação, ou seja, tornar visível para o público externo ações que vêm ocorrendo no, repercutindo uma boa imagem. No entanto, a relevância atribuída ao fator nos discursos leva a um indício do grande potencial, ainda latente, incumbido à divulgação. Fatores pouco citados, mas com bastante ênfase, foram: associação da marca institucional a ações já existentes e conhecidas em seus devidos meios, e conselhos para o fortalecimento da marca, como investir em marketing, melhorar níveis de ensino e investir em mídias sociais ou criar brindes.

Outros fatores citados, com menor ênfase, são: expansão física da instituição, com a inauguração de novos campi em outras cidades do estado; projeto de transformação da instituição em universidade tecnológica, e diversificação/aumento do número de cursos disponíveis. Deve ser dado destaque para o fator que remete à tradição da instituição no ensino técnico, levando em consideração sua história. Tal fator, apesar de igualmente citado, não somente foi mencionado sem muito realce, mas também, em uma das ocasiões, empregado com conotação negativa, como estigma.

Poucos se referiram à marca da escola como marca forte, sendo eles, porém, bastante enfáticos em suas opiniões. Fatores igualmente pouco citados são qualidade do ensino e contratação de novos servidores e parcerias nacionais, além da valorização interna da marca, citada apenas de forma neutra. Outros fatores mencionados por algum dos en- 
trevistados foram: bom nível dos alunos que entram na instituição; educação a distância; parcerias internacionais, e eventos que ocorrem nos campi da instituição. A seguir, a figura mostra os fatores em ordem decrescente de frequência absoluta em que foram mencionados (figura 6).

Figura 6 - Frequências absolutas dos fatores em ordem decrescente

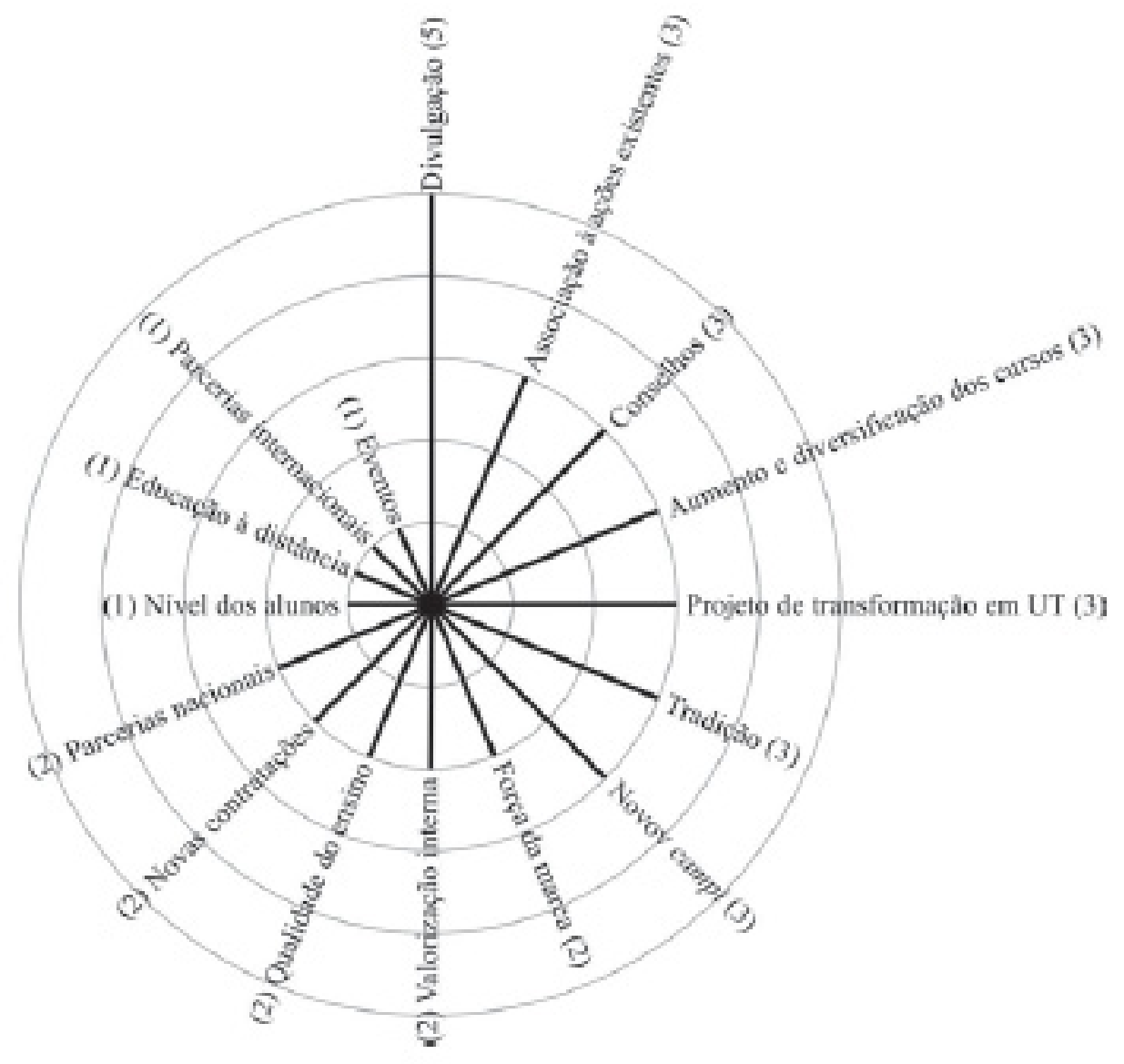

Fonte: Elaborado pelos autores.

Os fatores mais citados e com maior ênfase no questionamento sobre o sucesso da marca foram história da instituição e continuidade de seu crescimento. Vale ressaltar, entretanto, que novamente houve indagações negativas a respeito. Outros fatores bastante lembrados foram: bom nível dos alunos que ingressam na instituição, aliado à qualidade do ensino; referência aos servidores qualificados; bom nível dos profissionais formados pela instituição, e alusões ao reconhecimento pelo mercado, constituindo o tema geral ensino, que lidera a discussão sobre razões para o sucesso da marca.

Nos discursos analisados, foram percebidas também algumas alusões a problemas encontrados na instituição, sempre com menor peso que os fatores positivos apontados. A divulgação da escola também foi lembrada, tanto positiva quanto negativamente. Finalmente, foi destacada, em uma das entrevis- 
tas, a ligação emocional de alunos e servidores com a escola, sua estrutura com jardins e sua comunidade. A seguir, a figura mostra os fatores, em ordem decrescente de frequência absoluta em que foram mencionados (figura 7).

Figura 7 - Frequências absolutas dos fatores em ordem decrescente

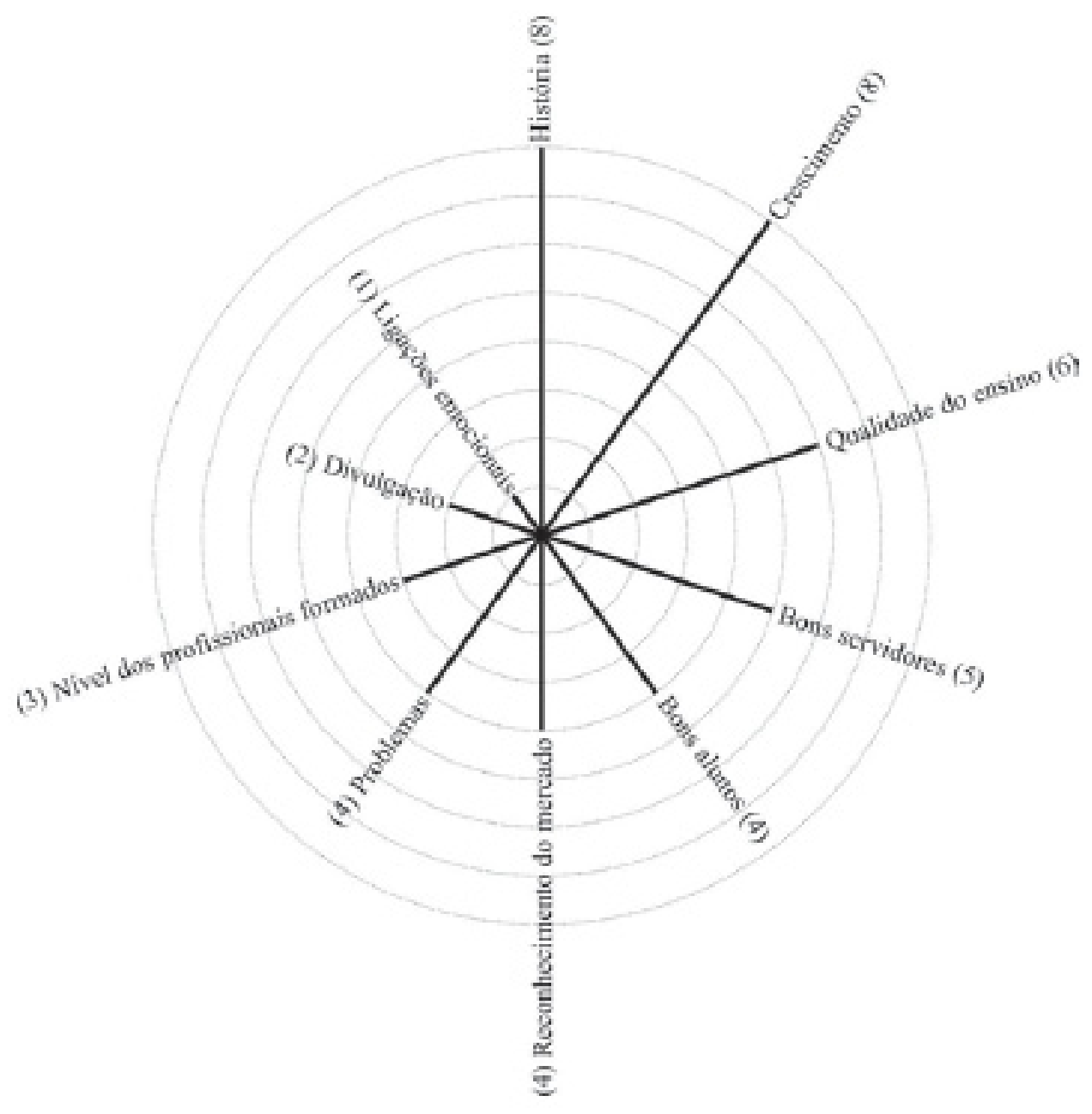

Fonte: Elaborado pelos autores.

\section{Defasagens entre estratégia da identida- de da marca e prática}

A ordenação dos fatores obtida nas entrevistas suporta algumas das conclusões expostas anteriormente. A grande importância dispensada ao ensino técnico e à imagem da fachada do campus principal, primeiro e mais tradicional, reafirma a relevância da tra- dição da marca, da história da instituição. 0 conjunto de alunos e os professores em suas aulas remetem à questão do ensino, líder na discussão sobre razões para o sucesso da marca. A imagem de alunos reunidos pode se relacionar também ao ambiente de amizade e às ligações emocionais com colegas da instituição. Os eventos e a estrutura da instituição, apesar de terem sido citados apenas 
Uma pesquisa aplicada na identidade da marca. 0 caso de organização pública de ensino no Brasil

timidamente anteriormente, aparecem com evidência como influenciadores da marca.

Projetos - da extensão ou do ensino - conquistaram boas posições, retratando o fator citado sobre a importância da divulgação de ações que vêm ocorrendo no centro. Os fatores relacionados ao servidor - como cursos de qualificação interna, comemorações entre servidores e premiações conferidas a eles - foram ordenados nas últimas colocações, evidenciando que os servidores não veem, em geral, sua ligação e importância para a marca. O quadro 3 mostra os fatores mais vezes ordenados em cada posição. Evidencia também o grande contraste entre o que os entrevistados pensam sobre o que influencia as imagens interna e externa da marca, pois, fora a qualidade de ensino, nenhum outro fator, entre os cinco primeiros de um lado, se repete no outro.

Quadro 3 - Fatores mais ordenados em cada posição

\begin{tabular}{|c|c|}
\hline Imagem externa & Imagem interna \\
\hline Qualidade de ensino ( $6 x)$ & Qualidade de ensino ( $4 x$ ) \\
\hline Demanda do mercado ( $5 x)$ & $\begin{array}{l}\text { Objetivos organizacionais claros }(2 x) \\
\text { Qualidade de ensino }(2 x) \\
\text { Boa relaçäo entre os servidores }(2 x)\end{array}$ \\
\hline Participação e promoção de eventos (2x) & $\begin{array}{l}\text { Liderança }(2 x) \\
\text { Infraestrutura da organizaçăo }(2 x) \\
\text { Cultura organizacional }(2 x)\end{array}$ \\
\hline $\begin{array}{l}\text { Participação e promoção de eventos }(2 x) \\
\text { Sinergia com a comunidade }(2 x)\end{array}$ & Ambiente agradável $(3 x)$ \\
\hline Sinergia com a comunidade $(2 x)$ & $\begin{array}{l}\text { Efetividade, eficiência, empatia no serviço }(2 x) \\
\text { Treinamento, reconhecimento e autonomia dos servidores }(2 x)\end{array}$ \\
\hline $\begin{array}{l}\text { Comunicaçäo formal externa ( } 3 x) \\
\text { Ambiente agradável }(3 x)\end{array}$ & Não houve concordaincia \\
\hline $\begin{array}{l}\text { Comunicaçäo formal interna }(2 x) \\
\text { Ambiente agradável }(2 x)\end{array}$ & Cultura organizacional $(2 x)$ \\
\hline $\begin{array}{l}\text { Divulgação na midia }(2 x) \\
\text { Cultura organizacional }(2 x)\end{array}$ & $\begin{array}{l}\text { Efetividade, eficiência, empatia no serviço (2x) } \\
\text { Liderança }(2 x)\end{array}$ \\
\hline $\begin{array}{l}\text { Participação e promoção de eventos }(2 x) \\
\text { Boa relaçäo entre os servidores }(2 x)\end{array}$ & Não houve concordäncia \\
\hline
\end{tabular}


Isabela Menezes da Silva Devonish - Osvaldo Luiz Gonçalves Quelhas - Sérgio França - Marcelo Meiriño

Continuação...

\begin{tabular}{|c|c|c|}
\hline 0 & Cultura organizacional (4x) & $\begin{array}{l}\text { Comunicaçäo formal interna }(2 x) \\
\text { Sinergia com a comunidade }(2 x) \\
\text { Boa relaçäo entre os servidores }(2 x)\end{array}$ \\
\hline 1 & $\begin{array}{l}\text { Objetivos organizacionais claros }(2 x) \\
\text { Comunicaçäo formal interna }(2 x)\end{array}$ & $\begin{array}{l}\text { Ambiente agradável }(2 x) \\
\text { Objetivos organizacionais claros }(2 x)\end{array}$ \\
\hline 2 & $\begin{array}{l}\text { Liderança }(3 x) \\
\text { Comunicaçäo formal interna }(3 x)\end{array}$ & Comunicaçäo formal externa ( $3 x)$ \\
\hline 3 & Comunicaçäo formal interna $(3 x)$ & Design $(2 x)$ \\
\hline 4 & $\begin{array}{l}\text { Divulgação na midia }(2 \mathrm{x}) \\
\text { Cultura organizacional }(2 \mathrm{x}) \\
\text { Divulgação em outras instituiçöes }(2 \mathrm{x}) \\
\text { Comunicaçäo formal externa }(2 \mathrm{x})\end{array}$ & Comunicação formal interna $(2 x)$ \\
\hline 5 & Boa relaçäo entre os servidores ( $4 \mathrm{x}$ ) & Design $(3 x)$ \\
\hline 6 & & $\begin{array}{l}\text { Divulgação na mídia (3x) } \\
\text { Participação e promoção de eventos }(3 x)\end{array}$ \\
\hline 7 & & Divulgaçäo em outras instituiçöes ( $3 x$ ) \\
\hline
\end{tabular}

Fonte: Elaborado pelos autores

Ao serem questionados sobre o que necessita melhorar, os entrevistados indicaram fatores relacionados à comunicação, com reconhecida importância para a estratégia, evidenciando sua atual deficiência. Outro fator que requer atenção especial é a infraestrutura física da organização, que, mesmo sendo considerado um poderoso fator para influenciar a imagem da organização, recebeu duras críticas. Liderança e ambiente agradável, grandes influenciadores da imagem interna segundo o tópico anterior, não foram citados, assim como a demanda do mercado, o que pode sugerir, se levarmos em conta ainda os discursos livres, que contam com níveis satisfatórios.

\section{DISCUSSÃO DOS RESULTADOS}

Nesta seção, com base nos resultados descritos no tópico anterior e segundo Aaker (2007), apresenta-se o diagnóstico da identidade da marca da OPE. Realizou-se em várias etapas, que deveriam incluir: (1) identificação das dimensões centrais da marca; (2) consideração da proposição de valor; (3) inclusão de elementos de credibilidade; (4) estabelecimento das bases de relaciona- 
mento com o usuário para determinação da identidade nuclear e da identidade externa da marca. Propõe-se, ao final deste tópico, a Matriz de Construção da Identidade da Marca da OPE.

\section{Reconhecimento da identidade da marca}

As categorias detectadas nas respostas, relacionadas ao aluno, foram agrupadas em seis temas: (a) tradição, em alusão à história da antiga Escola Técnica e o reconhecimento de outras instituições públicas; (b) reconhecimento pelo mercado de trabalho e oportunidades geradas; (c) continuidade do ensino técnico ao universitário; (d) qualidade do ensino; (e) respeito à diversidade, cidadania e maturidade adquirida pelos alunos; (f) facilidades, combinando referências à localização do campus da instituição, boa definição e organização dos horários das aulas e o fato de professores e servidores serem de fácil acesso.

Em relação ao servidor, as respostas podem ser agrupadas nos temas: (a) serviço público, composto pelo destaque à imagem ruim que o servidor tem, em geral, conseIhos para levar a sério o trabalho, mudando essa má reputação, horizonte de mudanças no serviço público e estabilidade; (b) Desenvolvimento da instituição; (c) facilidades para obter recursos na própria instituição. Outro aspecto é relacionado à proximidade entre as pessoas, o que agiliza processos, localização da instituição, salário e oportunidades de crescimento profissional; (d) clima institucional amistoso, rica experiência, contato com o verde no jardim interno e competição entre os departamentos da organização.

\section{Como é gerida a marca}

Os temas evidenciados nas respostas sobre a presente atuação da marca foram: (a) questões sobre a marca referentes à sua força efetiva, à divulgação da marca, à sua valorização interna, à associação da marca a ações existentes - da extensão ou do ensino -, e a conselhos para seu fortalecimento; (b) ensino, incluindo aumento e diversificação dos cursos, bom nível dos alunos, educação a distância e qualidade do ensino em si; (c) projeto de transformação em universidade tecnológica; (d) novas contratações de funcionários, permitindo renovação nos recursos humanos; (e) parcerias, nacionais e internacionais; (f) tradição da escola técnica; (g) expansão física da organização e sua interiorização com novos campi em outras cidades do estado; (h) eventos.

Com relação ao sucesso da marca, foram encontrados nas respostas os seguintes temas: (a) história da instituição e sua tradição desde a Escola Técnica; (b) contínuo crescimento da escola; (c) ensino, representado pela menção aos bons alunos encontrados no centro, aos professores e demais servidores, qualificados e admitidos por concursos, ao alto nível dos profissionais formados pela escola, à qualidade do ensino nos cursos e ao reconhecimento que o mercado tem pela instituição; (d) referências a possíveis problemas percebidos na instituição; (e) divulgação do centro e suas ações, aumentando sua visibilidade; (f) ligações emocionais com a escola, seu espaço físico e a comunidade interna.

\section{Defasagens entre estratégia da marca e prática}


Em resposta à solicitação de ordenar fatores de acordo com sua importância, a qualidade de ensino teve destaque evidente, assim como a demanda do mercado. Além disso, cultura organizacional, ambiente agradável, infraestrutura da organização, efetividade, eficiência e autonomia nos serviços e participação e promoção de eventos obtiveram relevância. De maneira mais dispersa, liderança, boa relação entre os servidores e sinergia com a comunidade também tiveram destaque. Fatores relacionados diretamente somente ao funcionário foram ordenados como última opção por todos os entrevistados.

Os fatores mais indicados como problemáticos, apesar de sua reconhecida importân- cia para a estratégia, estão relacionados em sua maioria à comunicação da instituição. A comunicação formal, tanto interna quanto externa, por meio de jornal interno, intranet, site e mídias sociais, por exemplo, foi mencionada por quase todos os entrevistados como fator a ser melhorado. Divulgação na mídia e infraestrutura também foram fatores bastante criticados.

\section{Matriz da Identidade da Marca da OPE X}

A partir da descrição resumida dos resultados na seção 4, apresentada em 5.1, 5.2 e 5.3, construiu-se a Matriz de Identidade, ilustrada no Quadro 4. 
Uma pesquisa aplicada na identidade da marca. $\mathbf{O}$ caso de organização pública de ensino no Brasil

Quadro 4 - Matriz de Identidade de Marca de OPE

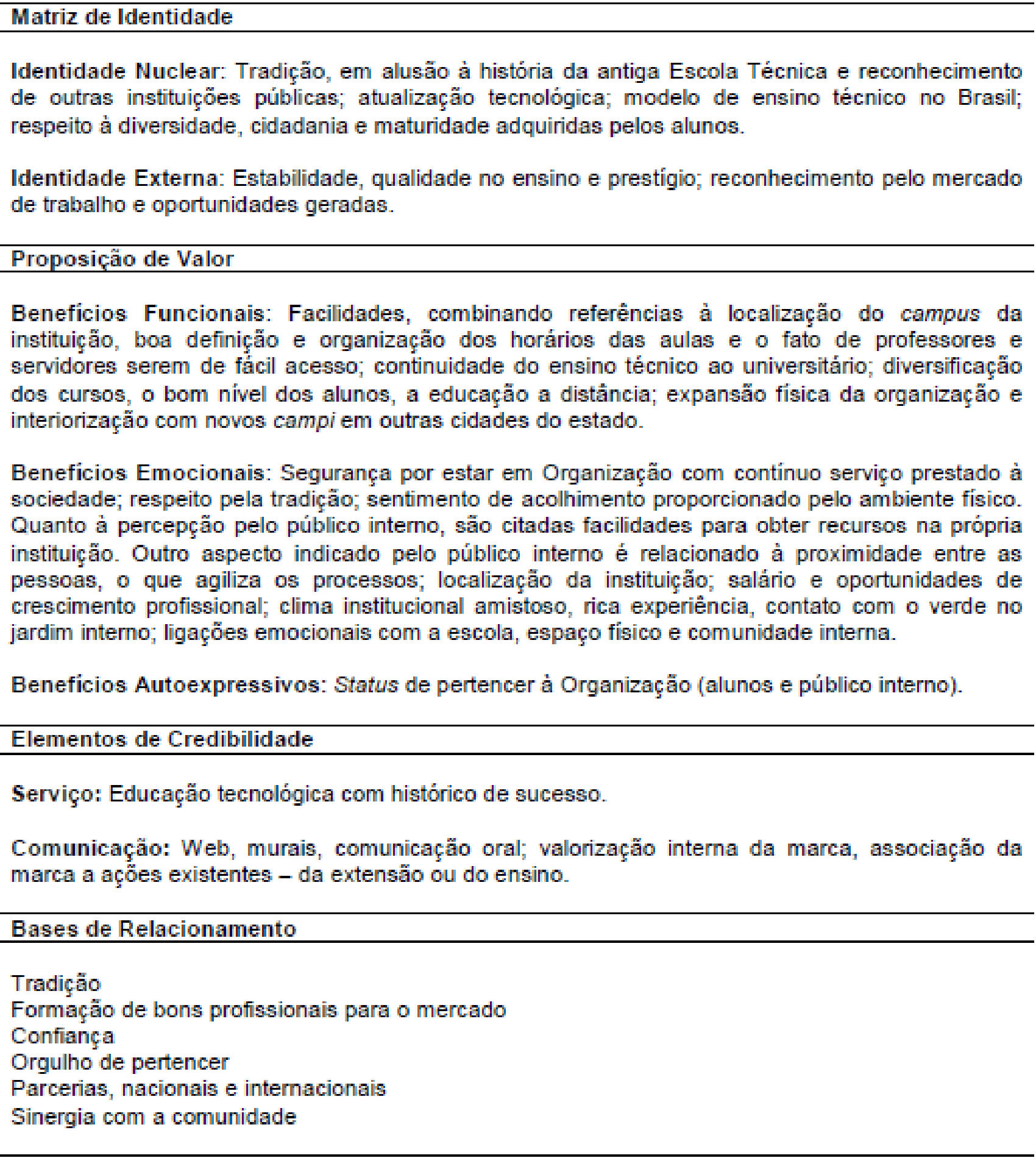

Fonte: Elaborado pelos autores. 


\section{CONCLUSÃO E SUGESTÃO DE NOVAS PESQUISAS}

As questões estabelecidas como foco deste trabalho tiveram a finalidade de identificar aspectos e características da identidade da marca em OPE, considerando suas particularidades de ser um serviço educacional inserido no setor público. Isso possibilitou apontar diretrizes para a definição de uma identidade e gestão de marcas adaptada ao caso específico, de modo a fortalecer sua imagem em relação à sociedade.

Ficou evidente na pesquisa, no caso de uma OPE, a importância da gestão interna da marca, que é um tema bastante discutido na literatura acadêmica. A literatura identificada busca mapear o que afeta a satisfação do público interno da organização, pois existe correlação entre a satisfação dele e a dos clientes/usuários. Entretanto, considerando os discursos dos gestores da marca da organização estudada, ficou claro que, além da baixa autoestima do funcionário público, ele não percebe sua importância para a marca. Inexiste conhecimento da relação da satisfação pessoal com a satisfação do público externo, o que é evidenciado quando fatores ligados ao funcionário público são ordenados sempre nas últimas posições como influenciadores da marca. A análise demonstrou também uma aparente segmentação entre os perfis docente e administrativo. Em geral, o servidor docente parece deter maior estima, enquanto o servidor de cargos administrativos sofre com níveis de desmotivação ainda maiores.

Para o servidor, outros fatores, mencionados a seguir, detêm maior atenção: vínculo com o mercado de trabalho, que possibilita alta taxa de empregabilidade de alunos e ex-alunos; qualidade do ensino, nivelada com outras conceituadas instituições; participação e promoção de eventos; bom nível e diversidade entre os alunos e tradição da instituição por sua história, embora esse último ponto seja encarado com receio pela possibilidade de impedir o crescimento da instituição para outros níveis e áreas. Ou seja, em geral, foram privilegiados fatores com relação direta ao ensino. A gestão atual da marca tem como destaque, segundo os entrevistados, ações isoladas de alguns grupos específicos e crescimento institucional, com a expansão física e a diversificação de cursos, embora eles admitam desconhecer um plano definido de gestão da marca.

A pesquisa revelou que os mecanismos e ações utilizados não satisfazem as necessidades da atual gestão de marcas na instituição, por isso é imprescindível recuperar as ferramentas de comunicação, internas e externas, e investir mais na infraestrutura básica dos prédios, fatores apontados constantemente nas entrevistas. Foi comprovado também o quanto as OPEs ainda são conservadoras em relação à apropriação de técnicas e ferramentas empresariais, não havendo consenso sobre uma identidade da marca definida institucionalmente ou de ações conscientes para sua gestão, nem estratégia definida ou mesmo responsável pela questão da marca, abandonando sua imagem a fatores não controlados.

Considerando a competitividade cada vez maior na área de educação, com instituições rivalizando local, nacional e mesmo internacionalmente, é urgente a elaboração de um plano de gestão de marca consciente, de modo a ocupar um posicionamento favorá- 
vel, com uma imagem positiva na mente do usuário/aluno, e obter vantagem competitiva pela identificação, reputação e lealdade. Outro ponto é que o próprio servidor público está em geral desiludido, mostrando apatia, desinteresse e descrença na organização, o que ajuda a propagar uma imagem ruim do serviço público e a desvalorização do servidor perante a sociedade. Melhorar a percepção da imagem externa da instituição pode contribuir para o crescimento do trabalhador e sua realização profissional. No caminho inverso, uma melhora na autoestima dos servidores, com uma prestação de serviços mais motivada e produtiva, ajudaria a consolidar a imagem da marca.

A aplicação das conclusões obtidas na pesquisa em outras organizações públicas no Brasil pode ser considerada, pois a OPE X é componente de uma rede de organizações estruturadas de forma equivalente e com os mesmos fins. No entanto, uma mudança na gestão da marca de instituições públicas, definindo sua identidade, não tem como obter sucesso, posicionando positivamente a imagem da instituição no imaginário do cliente/usuário, sem uma real reestruturação do serviço público e uma renovação de sua cultura, pois, como coloca Neves (2001, p. 89) "de facto, é desejável e possível actuar no domínio da imagem, mas esta acção só é eficaz quando suportada pelo correspondente funcionamento interno".

Diante do exposto e em conformidade com as diretrizes evidenciadas neste estudo, como sugestão de futura pesquisa, aponta-se o desenvolvimento de um modelo para definir a identidade e a gestão de marcas adaptado exclusivamente ao caso de instituições públicas de ensino, que busque e obtenha os resultados esperados. Comparações mais profundas entre instituições de ensino públicas e particulares também seriam de grande interesse, assim como estudos sobre os fatores que realmente influenciam a escolha da instituição de ensino no Brasil.

\section{REFERÊNCIAS}

Aaker, D. (1991). Managing brand equity Capitalizing on the value of a brand name. Nova York: The Free Press.

Aaker, D. (2007). Construindo marcas fortes. Porto Alegre: Bookman.

Aaker, J.; Joachimsthaler, E. (2000). Brand leadership. Brandweek.

Bardin, L. (1977). Análise de conteúdo. Lisboa: Edições 70.

Batista, F. (2004). Governo que aprende: gestão do conhecimento em organizações do executivo federal. Brasília: IPEA.

Bauer, M. W., \& Gaskell, G. (2002). Pesquisa qualitativa com texto, imagem e som: um manual prático. 2. ed. Petrópolis: Editora Vozes.

Black, J. The branding of higher education. Greensboro: sem works. Recuperado em 20 jun., 2012, de <www.semworks.net/papers/ wp_The-Branding-of-HigherEducation.php>.

Brasil. (1995). Plano diretor de reforma do aparelho do estado. Brasília: Câmara da Reforma do Estado.

Brodie, R., Whittome, J., \& Brush, G. (2009). Investigating the service brand: a custumer value perspective. Journal of Business Rese- 
arch, 62, 345-355.

CEFET/RJ - Centro Federal de Educação Tecnológica Celso Suckow da Fonseca. Plano de desenvolvimento institucional - PDI 2010-2014. Rio de Janeiro.

CEFET/RJ - Centro Federal de Educação Tecnológica Celso Suckow da Fonseca. Site do Centro Federal de Educação Tecnológica Celso Suckow da Fonseca. Recuperado em 10 nov., 2013, de <http://portal.cefet-rj. br>.

Chapleo, C. What defines succesul university brands? International Journal of Public Sector Management, 2010, 23 (2), 169-183.

Chen, C., Yu, C., Yang, S., \& Chang, H. (2004). A customer-oriented service-enhancement system for the public sector. Managing Service Quality, 14(5), 414-425.

Clayson, D., \& Haley, D. (2005). Marketing models in education: students as customers, products or partners. Marketing Education Review, 15(1), 1-10.

Cobra, M. Administração de marketing. 2. ed. São Paulo: Atlas, 1992.

Coelho, E. (2004). Gestão do conhecimento como sistema de gestão para o setor público. Revista do Serviço Público.

Curtis, T., Abratt, R., \& Minor, W. (2009). Corporate brand management in higher education: the case of ERAU. Journal of Product \& Brand Management, 18(6), 404-413.

De Chernatony, L. (1999). Brand management through narrowing the gap between brand identity and brand reputation. Journal of Marketing Management, 15(1-3), 157-179.

Durkin, M., Mckenna, S., \& Cummins, D. (2012). Emotional connections in higher education marketing. International Journal of Educational Management, 26(2), 153-161.

Foster, C., Punjaisri, K., \& Cheng, R. (2010). Exploring the relationship between corporate, internal and employer branding. Journal of Product \& Brand Management, 19(6), 401409.

Gil, A. C. (2002). Como elaborar projetos de pesquisa. 4. ed. São Paulo: Atlas.

Harvest Communications. The Brand Called $U$ : Branding and the University Experience. Recuperado em 20 jun., 2012, de <www. brandchannel.com/ images/ papers/ BrandCalledU.pdf>.

Heaney, J-G., \& Heaney, M. F. Services branding strategies: Using corporate branding to market educational institutions. In: Academy of World Business, Marketing and Mangement Development Conference. Rio de Janeiro. Recuperado em: 20 jun., 2012, de <http://researchonline.nd.edu.au/cgi/ viewcontent.cgi?article $=1000 \&$ context $=$ bus_ conference>.

Hood, D., \& Henderson, K. (2005). Branding in the United Kingdom public library service. New Library World, 106(1), 16-28.

Ivy, J. (2001). Higher education institution image: a correspondence analysis approach. International Journal of Educational Management, 15(6), 276-282. 
Uma pesquisa aplicada na identidade da marca. $\mathbf{O}$ caso de organização pública de ensino no Brasil

Judson, K. M., Aurand, T. W., Gorchels, L., \& Gordon, G. (2008). Building a university brand from within: university administrator's perspectives of internal branding Services Marketing Quarterly, 30(1), 54-68.

Keller, K. Gestão Estratégica de Marcas. (2005). São Paulo: Pearson Prentice Hall.

LAING, A. (2003). Marketing in the public sector: Towards a typology of public services. Marketing Theory, 3(4), 427-445.

Martins, J. R. (2006). Branding: um manual para você criar, gerenciar e avaliar marcas. 3. ed. São Paulo: Global Brands.

Martins, H. Uma análise dos paradigmas de administração pública à luz do contexto do estado social. Revista de Parcerias Estratégicas. Recuperado em: 15 jun., 2012, de: $<$ http://seer.cgee.org.br/>index.php/parcerias_estrategicas/article/view/634>.

Mayer, B. Case Study: The University of Denver. The Lawlor Review. Seção Our Points of View. Recuperado em 20 jun., 2012, de: $<$ www.thelawlorgroup.com/pov/review/v-xx-i-3-0/case-study-university-denver>.

Mazzarol, T. \& Soutar, G. Sustainable competitive advantage for educational institutions: a suggested model. International Journal of Educational Management, 1999, 13(6), 287-300.

Neves, A. (2001). Serviço público: para uma cultura de gestão na administração pública.

$\mathrm{Ng}$, I.; Forbes, J. (2009). Education as service: the understanding of university experience through the service logic. Journal of
Marketing of Higher Education, 19(1), 38-64.

Nguyen, T., Shirahada, K. \& Kosaka, M. A Consideration on University Branding Based on SDL (Service Dominant Logic): the lens of stakeholders' value co-creation. In: ICSSSM - 9th International Conference on Service Systems and Service Management, Shanghai. Recuperado em: 15 ago., 2012, de: <http://ieeexplore.ieee.org/pl/login.jsp?tp $=\&$ arnumber $=6252346 \&$ url $=\mathrm{http} \% 3 \mathrm{~A} \% 2 \mathrm{~F} \%$ 2Fieeexplore.ieee.org\%2Fxpls\%2Fabs_all. jsp\%3Farnumber\%3D6252346>.

Nogueira, L \& Portella, R. ABCBranding Uma proposta sobre meios e métodos para a implementação do Branding em Instituições de Ensino Superior. Trabalho de conclusão de curso (Pós-graduação MBA do Curso de Branding) - Universidade Anhembi Morumbi, São Paulo. Recuperado em: 15 nov., 2013, de <http://monografiabrandingeducacional. blogspot.com.br>.

Patton, M. (1990). Qualitative evaluation and research methods. Estados Unidos: SAGE Publications.

Pinar, M., Trapp, P., Girard, T. \& BOYT, T. (2011) Utilizing the brand ecosystem framework in designing branding strategies for higher education. International Journal of Educational Management, 25(7), 724-739.

Sá, J. W. B. (2005). Modelo de avaliação de desempenho da gestão organizacional pública. Dissertação de mestrado profissional em Administração, Universidade Estadual do Ceará, Fortaleza.

Selltiz, C. et al. (1975). Métodos de pesquisa nas relações sociais. São Paulo: EPU. 
Silva, E. L. \& Menezes, E. M. (2005). Metodologia da pesquisa e elaboração de dissertação. 4. ed. Florianópolis: UFSC.

Vásquez, R. P. (2011). Identidade de marca, gestão e comunicação. Revista Organicom, 2011.

Wheeler, A. (2003). Designing brand identity: a complete guide to creating, building, and maintaining strong brands. Nova Jersey: Hoboken.

Whelan, S., Davies, G., Walsh, M. \& Bourke, R. (2010). Public sector corporate branding and customer orientation. Journal of Business Research, 63, 1164-1171.

Yin, R. K. (2010). Estudo de caso: planejamento e métodos. 4 ed. Porto Alegre: Bookman. 